\title{
2. SYNOPSIS
}

\begin{tabular}{|l|l|}
\hline Name of Sponsor: I.R.I.S., 50 rue Carnot - 92284 Suresnes Cedex - & (For National Authority Use only) \\
France & \\
\hline Test drug & \\
Name of Finished Product: & \\
Name of Active Ingredient: gevokizumab S78989 & Page: \\
\hline $\begin{array}{l}\text { Individual Study Table } \\
\text { Referring to Part of the Dossier }\end{array}$ & Volume: \\
\hline
\end{tabular}

\section{Title of study:}

Open-label Safety and Pharmacokinetic Study of gevokizumab in Subjects with Behçet's Disease Uveitis.

Protocol No.: CL2-78989-001 (X052096)

EudraCT No 2011-003050-25

The description of the study protocol given hereafter includes the modifications of the substantial amendment to the protocol.

International coordinator

\section{Study centres:}

Seven centres in 3 countries included at least one patient: Republic of Korea - 11 included patients, Tunisia 2 included patients, Turkey -8 included patients.

Publication (reference): Not Applicable

Studied period:

Initiation date: 01 February 2012

Completion date: 12 August 2013

Phase of development of the study: II

\section{Objectives:}

The objective of this exploratory phase II study was to evaluate safety and to further document the pharmacokinetics of gevokizumab in subjects with Behçet's disease uveitis. In addition, the relationship between clinical and biological activity and the hypothetical minimal serum level threshold of $2 \mu \mathrm{g} / \mathrm{mL}$ gevokizumab was assessed. Anti-drug antibodies (ADA) formation (if any) was also assessed.

\section{Methodology:}

Prospective, international, multicentre, open-label, randomized, parallel-group, descriptive, clinical phase II study of gevokizumab in subjects with Behçet's disease uveitis affecting the posterior segment of the uveal tract of the eye.

Non-adaptive, centralized, balanced randomization with stratification on the type of subject (Acute or At Risk).

Patients were randomly allocated to one of the 3 dose regimen described below (Study Drug chapter).

This study was performed in strict accordance with Good Clinical Practice including the archiving of essential documents.

\section{Number of patients:}

Planned: 21 patients in total (i.e. 7 patients in each treatment regimen group) of whom at least 12 Acute patients if possible (with 4 in each dose regimen group).

Included: 21 patients ( 7 in the dose regimen 1, 6 in the dose regimen 2 , and 8 in the dose regimen 3 ), i.e. 17 Acute patients and 4 At risk patients.

\section{Diagnosis and main criteria for inclusion:}

To be eligible, all subjects had to have a history of Behçet's disease (diagnosis fulfilling the International Study Group Classification criteria) with ocular involvement in the posterior segment and past medical history of one or more acute exacerbations. At study entry, subjects had to be receiving background immunosuppressive treatment as per current practice defined for this study as immunosuppressive therapy (azathioprine $[\mathrm{AZA}] \leq 2.5 \mathrm{mg} / \mathrm{kg} / \mathrm{day}$, cyclosporin A $[\mathrm{CSA}] \leq 5 \mathrm{mg} / \mathrm{kg} / \mathrm{day}$, mycophenolate mofetil [MMF] $\leq 3 \mathrm{~g} /$ day, and methotrexate $[\mathrm{MTX}] \leq$ the highest tolerable dose, alone or in any combination) with oral corticosteroids ( $\leq 20 \mathrm{mg} /$ day prednisolone equivalent). 


\begin{abstract}
Diagnosis and main criteria for inclusion (Cont'd):
Acute subjects: To be eligible, subjects had to have had at least one posterior uveitis or panuveitis exacerbation in their past medical history, had to be experiencing an acute exacerbation of posterior uveitis or panuveitis at the time of selection, and had to be able to receive study drug within 72 hours of onset of the exacerbation.

At risk subjects: To be eligible, subjects had to have had at least one posterior uveitis or panuveitis exacerbation in the past 18 months, and evidence of vasculature leakage as measured by fundus fluorescein angiography (FFA).
\end{abstract}

\title{
Test drug:
}

Gevokizumab S 78989 intravenous (IV) or subcutaneous (SC) route according to the regimen group:

\begin{tabular}{|c|c|c|c|}
\hline $\begin{array}{l}\text { Regimen } \\
\text { Group }\end{array}$ & Population & $\begin{array}{c}\text { Planned number } \\
\text { of subjects }\end{array}$ & Dose Regimen \\
\hline $1 \mathrm{~A}$ & At Risk & 7 & $\begin{array}{l}60 \mathrm{mg} \text { IV gevokizumab followed by Q4W } 30 \mathrm{mg} \text { SC gevokizumab + stable } \\
\text { background treatments }\end{array}$ \\
\hline $1 \mathrm{~B}$ & Acute & & $\begin{array}{l}60 \mathrm{mg} \text { IV gevokizumab followed } 2 \text { or } 3 \text { weeks later by } 30 \mathrm{mg} \text { IV gevokizumab, } \\
\text { followed by Q4W } 30 \mathrm{mg} \text { SC gevokizumab + stable background treatments }\end{array}$ \\
\hline $2 \mathrm{~A}$ & At Risk & 7 & $\begin{array}{l}30 \mathrm{mg} \text { IV gevokizumab followed by Q4W } 30 \mathrm{mg} \text { IV gevokizumab + stable } \\
\text { background treatments }\end{array}$ \\
\hline $2 \mathrm{~B}$ & Acute & & $\begin{array}{l}30 \mathrm{mg} \text { IV gevokizumab followed } 2 \text { or } 3 \text { weeks later by } 30 \mathrm{mg} \text { IV gevokizumab, } \\
\text { followed by Q4W } 30 \mathrm{mg} \text { IV gevokizumab + stable background treatments }\end{array}$ \\
\hline $3 \mathrm{~A}$ & At Risk & 7 & $\begin{array}{l}60 \mathrm{mg} \text { IV gevokizumab followed by Q4W } 60 \mathrm{mg} \text { SC gevokizumab + stable } \\
\text { background treatments }\end{array}$ \\
\hline $3 \mathrm{~B}$ & Acute & & $\begin{array}{l}60 \mathrm{mg} \text { IV gevokizumab followed } 2 \text { or } 3 \text { weeks later by } 60 \mathrm{mg} \text { IV gevokizumab, } \\
\text { followed by Q4W } 60 \mathrm{mg} \text { SC gevokizumab }+ \text { stable background treatments }\end{array}$ \\
\hline
\end{tabular}

Q4W: every 4 weeks, IV: intravenous, SC: subcutaneous

Batch No.: S78989 $30 \mathrm{mg} / \mathrm{mL}$ : L0040456

Comparator (Reference product and/or placebo): Not applicable.

Duration of treatment:

Treatment periods:

Acute subjects:

- Part 1 - control response period: subject received the first administration of gevokizumab at Day CR0. Five visits were scheduled in order to assess response to the first administration of gevokizumab 1, 4, 7, 14 and 21 days after study drug administration. If subject reached response criteria after 2 weeks (Day 14, i.e. CR14) or 3 weeks (CR21), he/she started the part 2.

- Part 2 - maintain response period: if subjects met the response criteria, he/she received every 4 weeks (Q4W) gevokizumab until either D168 or they experienced an ocular exacerbation, whichever occurred first.

At risk subjects: subjects received Q4W gevokizumab until either D168 or they experienced an ocular exacerbation, whichever occurred first.

In Acute and At risk population, subjects who did not exacerbate and tolerated the study drug well continued receiving gevokizumab for an additional 6-month period (D336).

In case of ocular exacerbation occurring during the study, the investigator was requested per protocol to withdraw the patient from the study, whatever the severity.

In the event of premature study drug discontinuation, the subject received the most appropriate care in the opinion of the investigator, including rescue therapy for recurrent ocular exacerbations.

\section{Criteria for evaluation (all exploratory):}

Safety measurements conducted pre and post treatment (primary objective):

- Adverse events including those of specific interest (i.e. events, serious or non serious, related to malignancies, autoimmune diseases, infections, neutropenia, and allergies).

- Laboratory tests (local laboratories).

- Vital signs.

- ECG.

- Chest X-Ray. 


\section{Criteria for evaluation (all exploratory) (Cont'd):}

\section{Pharmacokinetic (PK) measurements:}

Serum gevokizumab concentrations were measured by XOMA using a validated electrochemiluminescence (ECL) bridging immunoassay.

For acute subjects: On Day CR0 and Day 0, PK samples were collected prior to the infusion, just before the end of the infusion, and 30 minutes after the end of the infusion. During Part 1, PK samples were collected at each visit. On all visits beginning at Day 28 (part 2 of the study), PK samples were collected pre-dose only (i.e. trough concentration samples).

For at risk subjects: On Day 0, PK samples were collected prior to the infusion, just before the end of the infusion, and 30 minutes after the end of the infusion. On all visits beginning at Day 28, PK samples were collected pre-dose only (i.e. trough concentration samples).

In addition, for acute and at risk patients, a PK sample was collected in the event of an exacerbation.

\section{Anti-drug antibodies (ADA):}

Serum samples for ADA testing had been collected at baseline and prior to each study drug administration and at study end. ADA formation had been determined using gevokizumab-specific ADA assays.

\section{Clinical and biological activity measurements (secondary objective):}

The following assessments were to be performed:

- Ophthalmological assessments at each visit (visual acuity [EDTRS], indirect ophthalmoscopy assessing anterior chamber and vitreous scores [SUN Working Group Grading Scheme], and fundus score [BenEzra Uveitis Scoring System], also documented by photographs).

- Fundus Fluorescein Angiography (FFA) analysis (Angiography Scoring for Uveitis Working Group).

- Optical Coherence Tomography (OCT) analysis.

- Numbers of subjects with ocular exacerbation (as defined per protocol; see below).

- For acute subjects, number of subjects responders to gevokizumab (as defined per protocol; see below).

- High-sensitive C-Reactive Protein (hs-CRP), Erythrocyte Sedimentation Rate (ESR) and Cytokines as inflammatory markers.

Non-ocular manifestations of Behçet's disease.

Definitions of "response" and "exacerbation"

- Definition of exacerbation for purposes of entering study (Acute subjects only) - Any of the following in the worst (index) eye:

- $\geq 2+$ vitreous haze $(\mathrm{VH})$ score with or without anterior chamber cell involvement (SUN).

- Documented $\geq 15$-letter ETDRS or 2-line Snellen decrease in Best Corrected Visual Acuity (BCVA) attributed to exacerbation of ocular inflammation secondary to Behçet's disease.

- Presence of new active retinal infiltrates and/or acute retinal vasculitis (RI/RV).

- Definition of response for purposes of entering Part 2 (Acute subjects only) - To be considered a responder to gevokizumab in Part 1 (at each visit of Part 1), subjects had to experience a response to an initial IV infusion of gevokizumab on or before Day 21. A response was defined as any of the following in the index eye without any deterioration from baseline in the other two parameters (as far as they were assessable at baseline), and no exacerbation in either eye:

- Improvement in vitreous haze, with or without anterior chamber cell involvement, by at least a 2-unit change on a scale of 0 to $4+(\mathrm{SUN})$.

- $\geq$ 15-letter ETDRS improvement in BCVA.

- Resolution of baseline retinal infiltrates and acute signs of vasculitis.

- Definition of exacerbation for purposes of assessing maintenance of response (all subjects) - Any of the following compared to baseline (Day 0) in either eye:

- Worsening in vitreous haze, with or without anterior chamber cell involvement, by a 2-unit change on a scale of 0 to $4+(\mathrm{SUN})$.

- $\geq 15$-letter ETDRS decrease in BCVA.

- Emergence of retinal infiltrates or acute retinal vasculitis.

Other measurements (exploratory assessments not yet performed)

Pharmacogenomics assessment (optional), other omics assessments

Auto-antibody production 


\section{Statistical methods:}

Since the sample size was anticipated to be small, no formal statistical testing was planned to be performed between dose regimen groups. Descriptive statistics were to be provided by dose regimen groups for acute and at risk subjects as far as possible. Since only 4 at risk were randomised, only individual data were to be provided for these subjects.

Study outcome: Descriptive statistics were provided in the Randomised Set.

Safety analysis: Descriptive statistics were provided in the Safety Set.

\section{Pharmacokinetic analysis:}

Due to the sparse sampling of the PK design, the PK data from the CL2-78989-001 study were analyzed trough population PK approach. The whole body of PK data available at the time of the analysis was used for model building. So, the population pharmacokinetic model was developed using data from patients suffering from type 2 diabetes and Behçet's disease uveitis, collected after administration of intravenous or subcutaneous doses. Only the specific results on the CL2-78989-001 study PK data are presented in this clinical report. The following individual exposures (i.e. area under the concentration-time curve, AUC) were computed for each CL2-78989-001 study patient:

- $\mathrm{AUC}_{\text {last, }}$, the area under the concentration-time curve computed for each gevokizumab administration to the patient.

- $\mathrm{AUC}_{\mathrm{cum}}$, the area under the concentration-time curve computed over the whole period of treatment of the patient.

Considering the small number of patients and the high heterogeneity in dosing regimens and number of administered doses (one to 13 depending on the patient), it was not possible to compute accurate statistics on these parameters. Consequently, simulations were performed to accurately predict the typical exposure, the average and trough concentrations at steady state $\left(\mathrm{AUC}_{\tau, \mathrm{ss}}, \mathrm{C}_{\mathrm{av}, \mathrm{ss}}\right.$, and $\left.\mathrm{C}_{\text {trough,ss }}\right)$, for each dosing regimen. To do so, $1000 \mathrm{PK}$ profiles were simulated at steady state. Then, predicted $\mathrm{AUC}_{\tau, \mathrm{ss}}, \mathrm{C}_{\mathrm{av}, \mathrm{ss}}$, and $\mathrm{C}_{\text {trough,ss }}$ were computed by non-compartmental approach for each simulated profiles. Finally, descriptive statistics were computed for each dosing regimen.

To further investigate any potential PK/PD relationship, the correlation between gevokizumab PK and the potential biological markers and clinical outcome has been explored. In addition, an assessment was to be made of the correlation between drug exposure and any evidence of drug toxicity.

Efficacy analysis: Descriptive statistics were provided in the Randomised Set. 


\section{SUMMARY - CONCLUSIONS}

\section{STUDY POPULATION AND OUTCOME}

A total of 24 patients (18 acute patients and 6 at risk patients) were selected for the study. Among them, 21 patients ( 17 acute patients and 4 at risk patients) were included and randomly assigned to one of the 3 dose regimen for each subset. The distribution of acute/at risk patients in each subset according to the dose regimens was:

- Subset of acute patients: 6 patients in the dose regimen 1, 5 patients in the dose regimen 2 and 6 patients in the dose regimen 3.

- Subset of at risk patients: 1 patient in the dose regimen 1, 1 patient in the dose regimen 2 and 2 patients in the dose regimen 3.

The recruitment of patients with acute exacerbation was deliberately favoured in this study to evidence the acute efficacy of the study drug, and reached the at least 12 acute patients expected.

Disposition of randomised patients by group (in global and by study period) - Overall patients

\begin{tabular}{|c|c|c|c|c|}
\hline & & Acute patients & At risk patients & All \\
\hline Included (randomised) & n & 17 & 4 & 21 \\
\hline $\begin{array}{l}\text { Withdrawn during the overall study (ASSE-D336) due to } \\
\text { lost to follow-up } \\
\text { adverse event } \\
\text { lack of efficacy } \\
\text { protocol deviation } \\
\text { non-medical reason }\end{array}$ & $\begin{array}{l}\text { n }(\%) \\
\text { n }(\%) \\
\text { n }(\%) \\
\text { n }(\%) \\
\text { n }(\%) \\
\text { n }(\%)\end{array}$ & $\begin{array}{c}14(\mathbf{8 2 . 3 )} \\
- \\
8(47.1) \\
2^{\# \#}(11.8) \\
2^{\#}(11.8) \\
2(11.8)\end{array}$ & $\begin{array}{l}2(\mathbf{5 0 . 0}) \\
\quad- \\
2(50.0) \\
\quad- \\
- \\
-\end{array}$ & $\begin{array}{l}16(76.2) \\
\quad- \\
10(47.6) \\
2(9.5) \\
2(9.5) \\
2(9.5)\end{array}$ \\
\hline Completed the study (ASSE-D336) & n (\%) & 3 (17.6) & $1(25.0)$ & $4(19.0)$ \\
\hline $\begin{array}{l}\text { Withdrawn during the first 6-month period due to } \\
\text { lost to follow-up } \\
\text { adverse event } \\
\text { lack of efficacy } \\
\text { protocol deviation } \\
\text { non-medical reason }\end{array}$ & $\begin{array}{l}\text { n (\%) } \\
\text { n (\%) } \\
\text { n (\%) } \\
\text { n (\%) } \\
\text { n (\%) } \\
\text { n (\%) }\end{array}$ & $\begin{array}{c}12 \text { (70.6) } \\
- \\
7(41.2) \\
2^{\#}(11.8) \\
2^{\#}(11.8) \\
1(5.9)\end{array}$ & $\begin{array}{c}1(25.0) \\
- \\
1(25.0) \\
- \\
- \\
-\end{array}$ & $\begin{array}{c}13(61.9) \\
- \\
8(38.1) \\
2(9.5) \\
2(9.5) \\
1(4.8)\end{array}$ \\
\hline Completed the first 6-month period (ASSE-D168) & n (\%) & $5(29.4)$ & $3(75.0)$ & $8(38.1)$ \\
\hline On-going in the 6-month extension period (D168-D336) & n (\%) & $5(29.4)$ & $2 *(50.0)$ & $7(33.3)$ \\
\hline $\begin{array}{l}\text { Withdrawn during the 6-month extension period due to } \\
\text { adverse event } \\
\text { Non-medical reason }\end{array}$ & $\begin{array}{l}\text { n }(\%) \\
\text { n }(\%) \\
\text { n }(\%)\end{array}$ & $\begin{array}{c}2(\mathbf{1 1 . 8 )} \\
1(5.9) \\
1(5.9)\end{array}$ & $\begin{array}{l}1(25.0) \\
1(25.0) \\
\quad-\end{array}$ & $\begin{array}{l}3(14.3) \\
2(9.5) \\
1(4.8)\end{array}$ \\
\hline Completed the 6-month extension period (D168-D336) & n (\%) & $3(17.6)$ & $1(25.0)$ & $4(19.0)$ \\
\hline $\begin{array}{l}\text { Analysis Sets } \\
\text { Randomised Set (RS) } \\
\text { Safety Set }(\text { SS })^{* *} \\
\text { Pharmacokinetic Set (PK Set) })^{* * *}\end{array}$ & $\begin{array}{c}\text { n } \\
\text { n (\%) } \\
\text { n (\%) }\end{array}$ & $\begin{array}{l}17 \\
17(100) \\
17(100)\end{array}$ & $\begin{array}{c}4 \\
4(100) \\
4(100)\end{array}$ & $\begin{array}{l}21 \\
21(100) \\
21(100)\end{array}$ \\
\hline \multicolumn{5}{|c|}{$\begin{array}{l}\text { *: One patient withdrew his consent; **: All patients having received at least one dose of study treatment } \\
\text { ***: All patients treated with gevokizumab and from whom blood samples were collected with no deviations that affect the PK } \\
\text { interpretation. } \\
\text { \#: } 2 \text { acute patients in the dose regimen } 2 \text { (patients No.'s } 001410000500004 \text { and 00022) were withdrawn from the study } \\
\text { (respectively at CR1 and CR4 visits) due to positive QuantiFERON@-TB test results, as per local amendment to the protocol. } \\
\text { \#\#: One patient in the dose regimen } 3 \text { (No. 001 } 410000400001 \text { ) was withdrawn at CR14 due to worsening of uveitis coded as } \\
\text { Behçet's syndrome and vitreous haemorrhage (lack of efficacy). } \\
\%: \text { According to randomised patients }\end{array}$} \\
\hline
\end{tabular}

Regarding the main characteristics of patients at baseline in the Randomised Set (see table below), it should be noted that all patient included in the study fulfilled the IUSG (International Uveitis Study Group) classification criteria for Behçet's disease at selection (as requested by the protocol), except one patient who had only 2 out of the 3 criteria required (panuveitis and recurrent oral ulcers).

All acute patient presenting an acute Behçet's disease uveitis exacerbation at selection/inclusion visit (ASSE/CR0) were in conformity with the protocol definition of ocular exacerbation.

At the qualifying ocular exacerbation visit, a decrease in BCVA $\geq 15$ letters EDTRS was present in $12 / 17$ acute patients $(70.6 \%)$ and the presence of a new active retinal infiltrates and/or acute retinal vasculitis was reported in 13/17 acute patients (76.5\%). In all, 6/17 acute patients (35.3\%) had the three Behçet uveitis criteria $\mathrm{VH}+\mathrm{BCVA}+\mathrm{RI} / \mathrm{RV}$ associated when the patients were selected/included in the study. 


\begin{tabular}{|c|c|c|c|c|}
\hline \multicolumn{5}{|l|}{ SUMMARY - CONCLUSIONS (Cont'd) } \\
\hline \multicolumn{5}{|c|}{$\begin{array}{l}\text { Concerning non-ocular symptoms of Behçet's disease, all randomised patients (except one in the subset of a } \\
\text { risk patients) had at least one non-ocular symptom present at baseline (mostly skin lesions). }\end{array}$} \\
\hline \multicolumn{5}{|c|}{$\begin{array}{l}\text { Main baseline characteristics at selection included those for of Behçet's disease } \\
\text { in acute and at risk patients - Randomised Set }\end{array}$} \\
\hline & & $\begin{array}{l}\text { Acute patients } \\
\quad(\mathbf{N}=17)\end{array}$ & $\begin{array}{l}\text { At risk patients } \\
\qquad(N=4)\end{array}$ & $\begin{array}{c}\text { All } \\
(\mathrm{N}=\mathbf{2 1})\end{array}$ \\
\hline Age (years) & $\mathrm{n}$ & 17 & 4 & 21 \\
\hline & Mean \pm SD & $34.1 \pm 9.0$ & $33.5 \pm 12.0$ & $34.0 \pm 9.3$ \\
\hline & Median & 35.0 & 34.5 & 35.0 \\
\hline & Min ; Max & $21 ; 51$ & $20 ; 45$ & $20 ; 51$ \\
\hline Men & $\mathrm{n}(\%)$ & $13(76.5)$ & $3(75.0)$ & $16(76.2)$ \\
\hline Asian & $\mathrm{n}(\%)$ & $10(58.8)$ & $1(25.0)$ & $11(52.4)$ \\
\hline Other & $\mathrm{n}(\%)$ & $7(41.2)$ & $3(75.0)$ & $10(47.6)$ \\
\hline \multicolumn{5}{|l|}{ Criteria for diagnosis of Behçet's disease } \\
\hline Behçet's disease duration since diagnosis & $\mathbf{n}_{\text {obs }}$ & 17 & 4 & 21 \\
\hline (months) & $\begin{array}{r}\text { Mean } \pm \text { SD } \\
\text { Median } \\
\text { Min ; Max }\end{array}$ & $\begin{array}{c}45.4 \pm 42.9 \\
21.0 \\
0 ; 122\end{array}$ & $\begin{array}{c}41.5 \pm 38.8 \\
39.0 \\
5 ; 83\end{array}$ & $\begin{array}{c}44.6 \pm 41.3 \\
21.0 \\
0 ; 122\end{array}$ \\
\hline Non ocular symptoms & $\mathbf{n}_{\text {obs }}$ & 17 & 4 & 21 \\
\hline Recurrent oral ulcers & $\mathrm{n}(\%)$ & $17(100)$ & $4(100)$ & $21(100)$ \\
\hline Neurological findings & $\mathrm{n}(\%)$ & - & - & - \\
\hline Skin lesions & $\mathrm{n}(\%)$ & $13(76.5)$ & $4(100)$ & $17(81.0)$ \\
\hline Genital ulcers & $\mathrm{n}(\%)$ & $9(52.9)$ & $3(75.0)$ & $12(57.1)$ \\
\hline Arthralgia & $\mathrm{n}(\%)$ & $5(29.4)$ & $1(25.0)$ & $6(28.6)$ \\
\hline Fatigue & $\mathrm{n}(\%)$ & $5(29.4)$ & - & $5(23.8)$ \\
\hline Vascular findings & $\mathrm{n}(\%)$ & $1(5.9)$ & $1(25.0)$ & $2(9.5)$ \\
\hline Arthritis & $\mathrm{n}(\%)$ & $1(5.9)$ & - & $1(4.8)$ \\
\hline \multicolumn{5}{|l|}{ History of uveitis associated with Behçet's disease } \\
\hline Uveitis duration (months) & $\begin{array}{r}\quad \mathbf{n}_{\text {obs }} \\
\text { Mean } \pm \text { SD } \\
\text { Median } \\
\text { Min ; Max }\end{array}$ & $\begin{array}{c}17 \\
48.0 \pm 38.4 \\
25.0 \\
6 ; 114\end{array}$ & $\begin{array}{c}4 \\
35.3 \pm 35.8 \\
26.0 \\
5 ; 84\end{array}$ & $\begin{array}{c}\mathbf{2 1} \\
45.6 \pm 37.4 \\
25.0 \\
5 ; 114\end{array}$ \\
\hline $\begin{array}{l}\text { Type of uveitis } \\
\text { Posterior uveitis } \\
\text { Panuveitis }\end{array}$ & $\begin{array}{r}\mathbf{n}_{\text {obs }} \\
\mathrm{n}(\%) \\
\mathrm{n}(\%)\end{array}$ & $\begin{array}{c}17 \\
2(11.8) \\
15(88.2)\end{array}$ & $\begin{array}{c}4 \\
1(25.0) \\
3(75.0)\end{array}$ & $\begin{array}{c}\mathbf{2 1} \\
3(14.3) \\
18(85.7)\end{array}$ \\
\hline $\begin{array}{l}\text { Number of ocular exacerbations } \\
\text { In the previous } 2 \text { years }\end{array}$ & $\begin{array}{r}\mathbf{n}_{\mathbf{o b s}} \\
\text { Mean } \pm \text { SD } \\
\text { Median } \\
\text { Min ; Max }\end{array}$ & $\begin{array}{c}17 \\
3.8 \pm 1.6 \\
4.0 \\
1 ; 7\end{array}$ & $\begin{array}{c}4 \\
2.3 \pm 1.0 \\
2.5 \\
1 ; 3\end{array}$ & $\begin{array}{c}\mathbf{2 1} \\
3.5 \pm 1.6 \\
3.0 \\
1 ; 7\end{array}$ \\
\hline In the previous 12 months & $\begin{array}{r}\text { Mean } \pm \text { SD } \\
\text { Median } \\
\text { Min; Max }\end{array}$ & $\begin{array}{c}2.5 \pm 1.2 \\
2.0 \\
0 ; 5\end{array}$ & $\begin{array}{c}1.5 \pm 0.6 \\
1.5 \\
1 ; 2\end{array}$ & $\begin{array}{c}2.3 \pm 1.2 \\
2.0 \\
0 ; 5\end{array}$ \\
\hline In the previous 6 months & $\begin{array}{r}\text { Mean } \pm \text { SD } \\
\text { Median } \\
\text { Min ; Max }\end{array}$ & $\begin{array}{c}1.4 \pm 1.2 \\
1.0 \\
0 ; 3\end{array}$ & $\begin{array}{c}0.8 \pm 0.5 \\
1.0 \\
0 ; 1\end{array}$ & $\begin{array}{c}1.2 \pm 1.1 \\
1.0 \\
0 ; 3\end{array}$ \\
\hline Time from last exacerbation (months) & $\mathbf{n}_{\mathbf{o b s}}$ & 17 & 4 & 21 \\
\hline \multirow[t]{4}{*}{ Right eye } & $\mathrm{n}$ & 11 & 4 & 15 \\
\hline & Mean \pm SD & $5.3 \pm 3.8$ & $5.5 \pm 3.3$ & $5.3 \pm 3.5$ \\
\hline & Median & 4.0 & 6.0 & 5.0 \\
\hline & Min ; Max & $1 ; 12$ & $1 ; 9$ & $1 ; 12$ \\
\hline \multirow[t]{4}{*}{ Left eye } & $\mathrm{n}$ & 6 & - & 6 \\
\hline & Mean \pm SD & $5.7 \pm 4.0$ & - & $5.7 \pm 4.0$ \\
\hline & Median & 4.5 & - & 4.5 \\
\hline & Min ; Max & $2 ; 13$ & $0 ; 0$ & $2 ; 13$ \\
\hline
\end{tabular}




\begin{tabular}{|c|c|c|c|}
\hline \multicolumn{4}{|c|}{$\begin{array}{l}\text { SUMMARY - CONCLUSIONS (Cont'd) } \\
\text { SAFETY RESULTS } \\
\qquad \\
\text { Overall summary for adverse events }\end{array}$} \\
\hline & & $\begin{array}{l}\text { Acute patients } \\
\quad(\mathbf{N}=17)\end{array}$ & $\begin{array}{l}\text { At risk patients } \\
\quad(\mathbf{N}=4)\end{array}$ \\
\hline $\begin{array}{l}\text { Patients having reported } \\
\text { at least one emergent adverse event } \\
\text { at least one treatment-related emergent adverse event }\end{array}$ & $\begin{array}{l}\mathrm{n}(\%) \\
\mathrm{n}(\%)\end{array}$ & $\begin{array}{c}14(82.3 \%) \\
-\end{array}$ & $\begin{array}{c}4(100) \\
1(25.0 \%)\end{array}$ \\
\hline $\begin{array}{l}\text { Patients having experienced } \\
\text { at least one serious emergent event (including death) } \\
\text { at least one treatment-related serious adverse event }\end{array}$ & $\begin{array}{l}\mathrm{n}(\%) \\
\mathrm{n}(\%)\end{array}$ & $\begin{array}{c}4(23.5 \%) \\
-\end{array}$ & $\begin{array}{l}- \\
-\end{array}$ \\
\hline $\begin{array}{l}\text { Patients with treatment withdrawal } \\
\text { due to an adverse event } \\
\text { due to a serious adverse event } \\
\text { due a treatment-related adverse event } \\
\text { due a treatment-related serious adverse event }\end{array}$ & $\begin{array}{l}\mathrm{n}(\%) \\
\mathrm{n}(\%) \\
\mathrm{n}(\%) \\
\mathrm{n}(\%)\end{array}$ & $\begin{array}{l}10(58.8 \%) \\
1(5.9 \%) \\
\quad- \\
\quad-\end{array}$ & $\begin{array}{l}2(50.0 \%) \\
- \\
- \\
-\end{array}$ \\
\hline Participants who died & $\mathrm{n}(\%)$ & - & - \\
\hline
\end{tabular}

\section{Adverse events}

In the Safety Set, 14/17 acute patients (82.4\%) and 4/4 at risk patients reported at least one emergent adverse event during the treatment period.

No clear conclusion concerning the relationship between the dose regimens and adverse events could be drawn due to the small number of patients in each dose regimen.

In acute patients, the emergent adverse events most frequently reported (i.e. those reported by at least 3 acute patients) were Behçet's syndrome* (5/17 patients overall, 29.4\%) and cataract (3/17 patients, 17.6\%). In at risk patients, myalgia and oropharyngeal pain were reported in 2/4 patients each (the other emergent AEs were reported in one patient each).

No clear effect of the dose regimen was evidenced whatever the subset of patients.

*worsening of uveitis related to Behçet's disease (5 cases in 4 acute patients), and Behçet colitis ulceration/haematochezia (one case in one acute patient), were coded as "Behçet's syndrome" as prefered term.

In acute patients, most emergent adverse events were rated as mild or moderate $(84.6 \%$ of the total number of emergent adverse events). In at risk patients, all emergent adverse events were rated as mild or moderate.

Emergent adverse events were rated as severe in $15.4 \%$ of the total EAEs in acute patients, while no severe EAE was reported in at risk patients.

The incidence of treatment-related emergent adverse events (TEAEs) during the study was low, as no TEAEs were reported in acute patients and one treatment-related headache (not serious) was reported during the treatment period in at risk patients.

Overall, 3/17 acute patients (17.6\%) experienced a total of 6 emergent adverse event leading to treatment withdrawal: one patient had one case of worsening of uveitis (coded as Behçet's syndrome) and 2 cases of macular oedema (all rated as severe), one patient had one case of worsening of uveitis (coded as Behçet's syndrome) and one case of vitreous haemorrhage (both considered as serious), and one patient had one case of worsening of uveitis (coded as Behçet's syndrome). All the patients recovered. As regards the subset of patients at risk, no patient experienced an emergent adverse event leading to treatment withdrawal.

As regards emergent adverse events of specific interest (i.e. events of special interest, serious or non serious, related to malignancies, autoimmune diseases, infections, neutropenia, and allergies), 2/17 acute patients $(11.8 \%)$ reported 2 adverse events of specific interest: one (mouth) abscess, non-serious (immediately notified) and considered by the investigator as unrelated to the study drug and one serious adverse event of phaeochromocytoma considered as not malignant and not related to the study treatment by the investigator. In the subset of at risk patients, one patient reported 2 EAEs of specific interest, one pyelonephritis and one upper respiratory tract infection, both of mild intensity, non-serious, and considered by the investigator as unrelated to the study drug. All of these EAEs of specific interest resolved. 


\section{SUMMARY - CONCLUSIONS (Cont'd) \\ SAFETY RESULTS (Cont'd)}

No death occurred during the study whatever the subsets of patients. A total of $4 / 17$ acute patients $(23.5 \%)$ experienced 6 serious emergent adverse events: optic (nerve) atrophy (related to worsening of uveitic glaucoma) and uveitic glaucoma in one patient, worsening of uveitis coded as "Behçet's syndrome" and vitreous haemorrhage in one patient, cataract and phaeochromocytoma (one patient each). None of these events were considered by the investigator as related to the study treatment. Of these 4 patients, one having optic (nerve) atrophy did not recover. No patients at risk experienced serious adverse events during the overall study.

In all, emergent or not emergent adverse events (including SEAEs) led to premature treatment withdrawal in $10 / 17$ acute patients $(58.8 \%)$. In at risk patients, premature treatment withdrawal due to adverse events were reported in 2/4 patients. In all, 9 acute patients and 2 at risk patients experienced a worsening of uveitis coded as "Behçet's syndrome" and were therefore withdrew from the study as per protocol requirement.

Few biochemical and haematological emergent PCSA values (without specific pattern) were reported on treatment in the two subsets of patients i.e. in acute patients: 2 high values of potassium (1.2 ULN each), one high GGT (2.4 ULN) and one low lymphocytes (1.5 LLN), and in at risk patients: one low potassium (1.2 LLN), one high LDL-cholesterol (1.1 ULN), one high triglycerides (1.7 ULN) and one low haematocrit (1.2 LLN). It is useful to note that there was no observation of low neutrophil PCSA values, a laboratory parameter of interest of this study.

As regards vital signs (measured at pre-dose and after infusion), the overall mean Body Mass Index (BMI), Systolic/Diastolic Blood Pressure (SBP/SBP) and Heart Rate (HR) in acute patients tended globally to remain stable during the study.

Neither acute patients nor at risk patients reported an ECG abnormality considered as clinically significant by the investigator during the study. 


\section{SUMMARY - CONCLUSIONS (Cont'd) \\ PHARMACOKINETICS AND ANTI-DRUG ANTIBODIES RESULTS}

As regards PK analyses, results showed that although acute patients received an additional IV dose, the mean gevokizumab exposure at steady state was very similar for acute and at risk patients within each dose group. It illustrated the limited accumulation of gevokizumab in the serum following these dosing regimens. The mean value of $\mathrm{AUC}_{\tau, \mathrm{ss}}$ in group 3 was 2-fold higher than the mean value of $\mathrm{AUC}_{\tau, \mathrm{ss}}$ in group 1. This result was coherent with the administered SC doses (30 and $60 \mathrm{mg}$ in groups 1 and 3 , respectively). The same observations were made for $\mathrm{C}_{\mathrm{av}, \mathrm{ss}}$ and $\mathrm{C}_{\text {trough,ss. }}$. The steady state exposure after repeated IV administrations at the dose of $30 \mathrm{mg}$ (group 2) was higher than the steady state exposure after repeated SC administrations at the dose of $30 \mathrm{mg}$ (group 1) but lower than the one after repeated SC administration at the dose of $60 \mathrm{mg}$ (group 3). This observation was explained by the SC bioavailability of about $70 \%$.The range of predicted steady state exposure was larger for group 1 and 3 than for group 2, which illustrated the higher inter-individual PK variability after repeated SC administrations, compared to repeated IV administrations.

Descriptive statistics of the gevokizumab pharmacokinetic secondary parameters at steady state (in serum) computed from 1000 simulated PK profiles, in each dose regimen in at risk $(A)$ and acute $(B)$ patients

\begin{tabular}{|c|c|c|c|c|}
\hline $\begin{array}{l}\text { Dosing } \\
\text { Group }\end{array}$ & & $\begin{array}{c}\mathrm{AUC}_{\boldsymbol{\tau}, \mathrm{ss}} \\
(\mu \mathrm{g.day} / \mathrm{mL})\end{array}$ & $\begin{array}{c}C_{\text {av,ss }} \\
(\mu \mathrm{g} / \mathbf{m L})\end{array}$ & $\begin{array}{l}\mathrm{C}_{\text {trough,ss }} \\
(\mu \mathrm{g} / \mathrm{mL})\end{array}$ \\
\hline $1 \mathrm{~A}$ & $\begin{array}{r}\text { Mean } \pm \text { SD } \\
\left(5^{\text {th }} \text { quantile, median, } 95^{\text {th }}\right. \\
\text { quantile })\end{array}$ & $\begin{array}{c}126 \pm 63.1 \\
(38.5,117,241)\end{array}$ & $\begin{array}{c}4.49 \pm 2.25 \\
(1.37,4.17,8.61)\end{array}$ & $\begin{array}{c}3.62 \pm 2.07 \\
(0.922,3.23,7.71)\end{array}$ \\
\hline $1 \mathrm{~B}$ & $\begin{array}{r}\text { Mean } \pm \text { SD } \\
\left(5^{\text {th }} \text { quantile, median, } 95^{\text {th }}\right. \\
\text { quantile })\end{array}$ & $\begin{array}{c}124 \pm 57 \\
(42,115,230)\end{array}$ & $\begin{array}{c}4.42 \pm 2.04 \\
(1.5,4.1,8.23)\end{array}$ & $\begin{array}{c}3.54 \pm 1.88 \\
(0.959,3.23,7.06)\end{array}$ \\
\hline $2 \mathrm{~A}$ & $\begin{array}{r}\text { Mean } \pm S D \\
\left(5^{\text {th }} \text { quantile, median, } 95^{\text {th }}\right. \\
\text { quantile })\end{array}$ & $\begin{array}{c}183 \pm 69.5 \\
(92.3,171,315)\end{array}$ & $\begin{array}{c}6.55 \pm 2.48 \\
(3.3,6.12,11.3)\end{array}$ & $\begin{array}{c}4.4 \pm 2.36 \\
(1.11,4.06,8.63)\end{array}$ \\
\hline $2 \mathrm{~B}$ & $\begin{array}{r}\text { Mean } \pm \text { SD } \\
\left(5^{\text {th }} \text { quantile, median, } 95^{\text {th }}\right. \\
\text { quantile })\end{array}$ & $\begin{array}{c}182 \pm 64 \\
(94.4,174,303)\end{array}$ & $\begin{array}{c}6.49 \pm 2.29 \\
(3.37,6.2,10.8)\end{array}$ & $\begin{array}{c}4.31 \pm 2.2 \\
(1.18,4.00,8.26)\end{array}$ \\
\hline $3 \mathrm{~A}$ & $\begin{array}{r}\text { Mean } \pm \text { SD } \\
\left(5^{\text {th }} \text { quantile, median, } 95^{\text {th }}\right. \\
\text { quantile })\end{array}$ & $\begin{array}{c}250 \pm 125 \\
(76.9,233,480)\end{array}$ & $\begin{array}{c}8.93 \pm 4.47 \\
(2.75,8.32,17.1)\end{array}$ & $\begin{array}{c}7.21 \pm 4.11 \\
(1.84,6.44,15.3)\end{array}$ \\
\hline $3 B$ & $\begin{array}{r}\text { Mean } \pm \text { SD } \\
\left(5^{\text {th }} \text { quantile, median, } 95^{\text {th }}\right. \\
\text { quantile })\end{array}$ & $\begin{array}{c}247 \pm 113 \\
(84.1,230,459)\end{array}$ & $\begin{array}{c}8.82 \pm 4.05 \\
(3.00,8.2,16.4)\end{array}$ & $\begin{array}{c}7.05 \pm 3.73 \\
(1.92,6.45,14.1)\end{array}$ \\
\hline
\end{tabular}

$A U C_{\tau, s s}:$ exposure during a dosing interval $\left(\tau=28\right.$ days) at steady state, $C_{a v, s s}:$ average steady state concentration,

$C_{\text {trough,ss: }}$ trough concentration at steady state

A groups : at risk patients, $B$ groups: acute patients

1A: $60 \mathrm{mg} I V$ gevokizumab followed by $\mathrm{Q} 4 \mathrm{~W} 30 \mathrm{mg}$ SC gevokizumab

1B: $60 \mathrm{mg}$ IV gevokizumab followed 2 or 3 weeks later by $30 \mathrm{mg}$ IV gevokizumab, followed by Q4W $30 \mathrm{mg} S \mathrm{C}$ gevokizumab

2A: $30 \mathrm{mg} I V$ gevokizumab followed by $Q 4 W 30 \mathrm{mg} I V$ gevokizumab

2B: $30 \mathrm{mg} I V$ gevokizumab followed 2 or 3 weeks later by $30 \mathrm{mg}$ IV gevokizumab, followed by $Q 4 \mathrm{~W} 30 \mathrm{mg}$ IV gevokizumab

3A: $60 \mathrm{mg} I V$ gevokizumab followed by $Q 4 \mathrm{~W} 60 \mathrm{mg} S \mathrm{C}$ gevokizumab

3B: $60 \mathrm{mg} I V$ gevokizumab followed 2 or 3 weeks later by $60 \mathrm{mg}$ IV gevokizumab, followed by Q4W $60 \mathrm{mg}$ SC gevokizumab

Individual secondary $\mathrm{PK}$ parameters $\left(\mathrm{AUC}_{\mathrm{las}} \mathrm{t}, \mathrm{AUC}_{\mathrm{cum}}\right)$ are provided in appendix of this clinical report.

The gevokizumab pharmacokinetics was linear in the administered dose range and exhibited a bi-exponential decline with initial and terminal half-lives, clearance, and volume of distribution that are typical for a human antibody subject to a non-specific clearance mechanism. No PKPD relationship had been demonstrated based on the CL2-78989-001 data but it may be explained by the limited number of patients. Consequently, PKPD relationship will be further explored when additional data (from phase 3 uveitis studies) will be available. Since drug concentration observed at the time of ocular exacerbation onset during the study were higher (mean \pm SD of $6.01 \pm 2.20 \mu \mathrm{g} / \mathrm{mL}$ ) than the hypothetical minimal serum level threshold of $2 \mu \mathrm{g} / \mathrm{mL}$ gevokizumab observed in the POC study, this serum level could not be confirmed.

Results of gevokizumab specific ADA assays showed that neither acute patients nor at risk patients developed neutralizing ADA. It can be noticed that 2 acute patients were notified as reactive to the assay at D0 visit despite transitory non neutralizing ADA, for which titration was below the limit of quantification. 


\section{SUMMARY - CONCLUSIONS (Cont'd) \\ CLINICAL AND BIOLOGICAL ACTIVITY RESULTS}

\section{In acute patients}

Among the 17 randomised acute patients, $15(88.2 \%)$ were considered as responders according to the criteria of response defined in the protocol, regardless of the gevokizumab dose regimen, and $2(11.8 \%)$ were prematurely withdrawn before CR21 evaluation (end of part I). Of these 2 patients, one was withdrawn at CR4 due to the notification of the positive response to QuantiFERON® $®$-TB test after inclusion (and thus was not evaluated for the response to gevokizumab at CR14/21). The other patient was withdrawn at CR14 as she did not respond to either gevokizumab or high dose of corticosteroids, but improved after vitrectomy (intravitreal haemorrhage associated with a worsening of uveitis).

The first response was observed as early as from the first day after the initial injection (CR1), and most patients responded during the first week i.e. $11 / 15$ patients (73.3\%) responded before or at CR7. At CR4, $8 / 15$ patients $(53.3 \%)$ had already responded to gevokizumab. The criterion of response most frequently observed during the overall part I was an improvement of the visual acuity (BCVA) of $\geq 15$ letters, observed in $10 / 15$ patients $(66.7 \%)$, i.e. $5 / 6,1 / 4$ and $4 / 5$ patients in the dose regimen 1,2 and 3 respectively.

Evaluation of patient's response to gevokizumab (per protocol criterion) in acute patients during the part I of the study - Randomised Set

\begin{tabular}{|c|c|c|c|c|c|c|}
\hline & & & & Acute patients & & \\
\hline & & & $\begin{array}{c}\text { Dose regimen } 1 \\
(N=6)\end{array}$ & $\begin{array}{c}\text { Dose regimen } 2 \\
\qquad(N=5)\end{array}$ & $\begin{array}{c}\text { Dose regimen } 3 \\
(N=6)\end{array}$ & $\begin{array}{c}\text { All } \\
(N=17)\end{array}$ \\
\hline All & & $\mathbf{n}$ & 6 & 5 & 6 & 17 \\
\hline Non responder* & & $\mathrm{n}(\%)$ & - & $1(20.0)$ & $1(16.7)$ & $2(11.8)$ \\
\hline Responder & & n $(\%)$ & $6(100)$ & $4(80.0)$ & $5(83.3)$ & $15(88.2)$ \\
\hline First response & $\begin{array}{l}\text { at CR01 } \\
\text { at CR04 } \\
\text { at CR07 } \\
\text { at CR14 } \\
\text { at CR21 }\end{array}$ & $\begin{array}{l}\text { n (\%) } \\
\text { n (\%) } \\
\text { n (\%) } \\
\text { n (\%) } \\
\text { n (\%) }\end{array}$ & $\begin{array}{c}1(16.7) \\
1(16.7) \\
2(33.3) \\
2(33.3) \\
-\end{array}$ & $\begin{array}{c}1(20.0) \\
1(20.0) \\
1(20.0) \\
1(20.0) \\
-\end{array}$ & $\begin{array}{c}- \\
4(66.7) \\
- \\
- \\
1(16.7)\end{array}$ & $\begin{array}{l}2(11.8) \\
6(35.3) \\
3(17.7) \\
3(17.7) \\
1(5.9)\end{array}$ \\
\hline
\end{tabular}

$N$ : Number of acute patients by dose regimen; $n:$ Number of patients; $\%:(n / N) x 100$

Dose regimen 1: $60 \mathrm{mg}$ IV gevokizumab followed 2 or 3 weeks later by $30 \mathrm{mg}$ IV gevokizumab, followed by $Q 4 \mathrm{~W} 30 \mathrm{mg} S \mathrm{C}$ gevokizumab + stable background treatments

Dose regimen 2: $30 \mathrm{mg} \mathrm{IV} \mathrm{gevokizumab} \mathrm{followed} 2$ or 3 weeks later by $30 \mathrm{mg} \mathrm{IV}$ gevokizumab, followed by Q4W $30 \mathrm{mg}$ IV gevokizumab + stable background treatments

Dose regimen 3: $60 \mathrm{mg}$ IV gevokizumab followed 2 or 3 weeks later by $60 \mathrm{mg}$ IV gevokizumab, followed by Q4W $60 \mathrm{mg} S \mathrm{C}$ gevokizumab + stable background treatments

* 2 patients (each in dose regimen 2 and 3), were early withdrawn from the study. One (No. 001410000500022$)$ due to the notification of the positive response to QuantiFERON®-TB test (QuantiFERON@-TB test was done before inclusion, results were available after first injection of gevokizumab), the other (patient No. 001410000400001 ) as he did not responded to either gevokizumab or high dose of corticosteroids, but improved after vitrectomy (patient had intravitreal haemorrhage associated with a worsening of uveitis).

Therefore cumulative response rate observed at each visit was $13.3 \%(2 / 15$ responders $)$ on CR01, $53.3 \%(8 / 15)$ on CR04, 73.3\% (11/15) on CR07, 93.3\% (14/15) on CR14 and 100\% (15/15) on CR21. Only one patient had a late answer at CR21.

When unplanned analyses focused on acute patients who were assessable on CR14 and CR21 (formal visits defined in the protocol for response assessment) i.e. 14 acute patients not prematurely withdrawn before CR21, the results indicated that all these patients (14/14) responded to the initial dose of gevokizumab.

According to this unplanned analysis, 10/14 patients (71.4\%) responded to gevokizumab before or at CR07 (at CR4, 8/15 patients had already responded to gevokizumab). The criterion of response most frequently observed was an improvement of the visual acuity (BCVA) of $\geq 15$ letters, observed in $9 / 14$ patients $(64.3 \%)$, i.e. $5 / 6,0 / 3$ and $4 / 5$ patients in the dose regimen 1,2 and 3 respectively.

Overall, the mean BenEzra score in index eye tended to improve in acute patients from baseline to each post baseline assessment until D336, irrespective of treatment arm.

The mean Fundus Fluorescein Angiography (FFA) total score in index eye of acute patients tended to improve from baseline to each post baseline assessment until D168, irrespective of treatment arm. Results were globally similar for FFA sub-scores in index eye of acute patients during the study. 


\section{SUMMARY - CONCLUSIONS (Cont'd) \\ CLINICAL AND BIOLOGICAL ACTIVITY RESULTS (Cont'd)}

During the part II of the study (D0-D336 period), 9/14 acute patients experienced a total of 12 ocular exacerbations, with a median time between randomisation and the first post-randomisation exacerbation of 3.2 months. The presence of active retinal infiltrates and/or acute retinal vasculitis alone (i.e. component $\mathrm{RI}$ alone, $\mathrm{RI}+\mathrm{RV}, \mathrm{RV}$ alone, without significant impact on visual acuity) was the main criterion of these ocular exacerbations, as it concerned 6/12 exacerbations. The presence of RI and/or RV associated with a worsening of vitreous haze occurred in $1 / 12$ ocular exacerbations.

When acute patients presented with an exacerbation during the part II of the study, the decrease of BCVA (at least 15 letters EDTRS) was less frequent (5/12 patients, 41.7\%) than at the qualifying exacerbation visit $(12 / 17$ patients, $70.6 \%)$. It should be noted that for one acute patient, ocular exacerbation occurred after unplanned tapering of corticosteroids.

As regards non-ocular Behçet's disease examination during the D0-D336 period, a total of 7 acute patients experienced at least one emergent non-ocular symptom related to Behçet's diseas i.e. 2 patients had fatigue, 1 had skin lesions, 1 patient had acne-like lesions/folliculitis and 3 had other abnormalities. Only two of these symptoms were reported as adverse event by the investigator.

Regarding the perception of the Behçet's disease activity, patients' self-assessments score and clinician's score tended to remain stable throughout the D0-D336 period. These results were in line with Behçet's disease activity indexes.

\section{In at risk patients}

Results in at risk patients subset have to be interpreted cautiously due to the low number of patients $(N=4)$.

No conclusion could be drawn in at risk patients concerning, central FFA scores and ophthalmologic assessments during the study due to the small size of this sample.

In all, $2 / 4$ patients at risk experienced a total of 3 ocular exacerbations during the study (mainly due to the presence of active retinal infiltrate). These $2 / 4$ at risk patients experienced their first post-randomisation exacerbations at 1.8 and 7.5 months respectively, since their randomisation in the study. No patient at risk experienced an exacerbation with significant impact on visual acuity. It should be noted that for one at risk patient, ocular exacerbations occurred after unplanned tapering of corticosteroids.

No patient at risk experienced emergent non-ocular symptom related to Behçet's disease during the D0-D336 period.

As regards the perception of Behçet's disease activity, the patient's and clinician's score tended to improve since D28 until D336 assessment, however due to the decrease of the number of patients since D112 visit, the results should be interpreted with caution. For Behçet's disease activity index, the score tended to remain stable throughout the D0-D336 period. 


\section{CONCLUSION}

This phase II study of gevokizumab in the treatment of subjects with Behçet's disease uveitis showed that the safety of gevokizumab, when administered on top of limited dose of corticosteroids and immunosuppressive drugs, was satisfactory with no serious adverse event related to the study drug. These safety data collected in patients treated with various fixed dose of SC and IV gevokizumab, confirmed the favourable safety profile observed in the proof of concept study (X052079; Gül et al, 2012). In this study, no clear relationship between the dose regimen and the safety profile was observed. Observed blood concentrations of gevokizumab were consistent with the values expected for these dosing regimens. However, the relationship between clinical and biological activity and the hypothetical minimal threshold of $2 \mu \mathrm{g} / \mathrm{mL}$ of gevokizumab serum level could not be demonstrated. No patient developed neutralizing ADA.

Among the 17 acute randomised patients, 15 patients $(88.2 \%)$ were responders and 2 patients $(11.8 \%)$ were prematurely withdrawn before CR21 of which one patient did not respond to gevokizumab and also did not respond to high dose of corticosteroids, but improved after vitrectomy (due to intravitreal haemorrhage). Considering patients evaluable at CR21, all patients (14/14) were responders. The response was rapid (mostly within 1 week) and could be observed from the first day (CR1). Overall these data indicate that gevokizumab safely and rapidly controlled acute ocular exacerbations of patients with Behçet's disease uveitis without the need for high dose of corticosteroids.

Eleven patients developed at least one Behçet's ocular exacerbation during the study, as expected in this relapsing disease where no drug is known to be curative today: 9 acute patients and 2 at risk patients. Most of these exacerbations (7/12 in acute patients, $3 / 3$ in at risk patients) were not associated with a significant decrease of BCVA (i.e. decrease by 15 letters ETDRS or more, attributed to exacerbation of ocular inflammation secondary to Behçet's disease). However the efficacy of gevokizumab on recurent ocular exacerbations could not be appropriately evaluated in the absence of a control group.

Due to the small sample size and the lack of control group, the results of this phase 2 study should be considered with caution.

Further studies are warranted to investigate gevokizumab's potential in the management of refractory Behçet's disease uveitis.

Date of the report: 21 July 2014

Version of the report: Final version 